\title{
Modeling of neuro-fuzzy system as a support in decision-making processes
}

\author{
Darko Božanić $^{1}$, Duško Tešić ${ }^{1}$, Dragan Marinkovic ${ }^{2}$, Aleksandar Milić ${ }^{1}$ \\ ${ }^{1}$ Military Academy, University of Defence in Belgrade, Belgrade, Serbia, \\ e-mail: dbozanic@yahoo.com, tesic.dusko@yahoo.com, milickm5@gmail.com. \\ ${ }^{2}$ Faculty of Mechanical Engineering and Transport Systems, TU Berlin, Berlin, Germany, \\ e-mail: dragan.marinkovic@tu-berlin.de
}

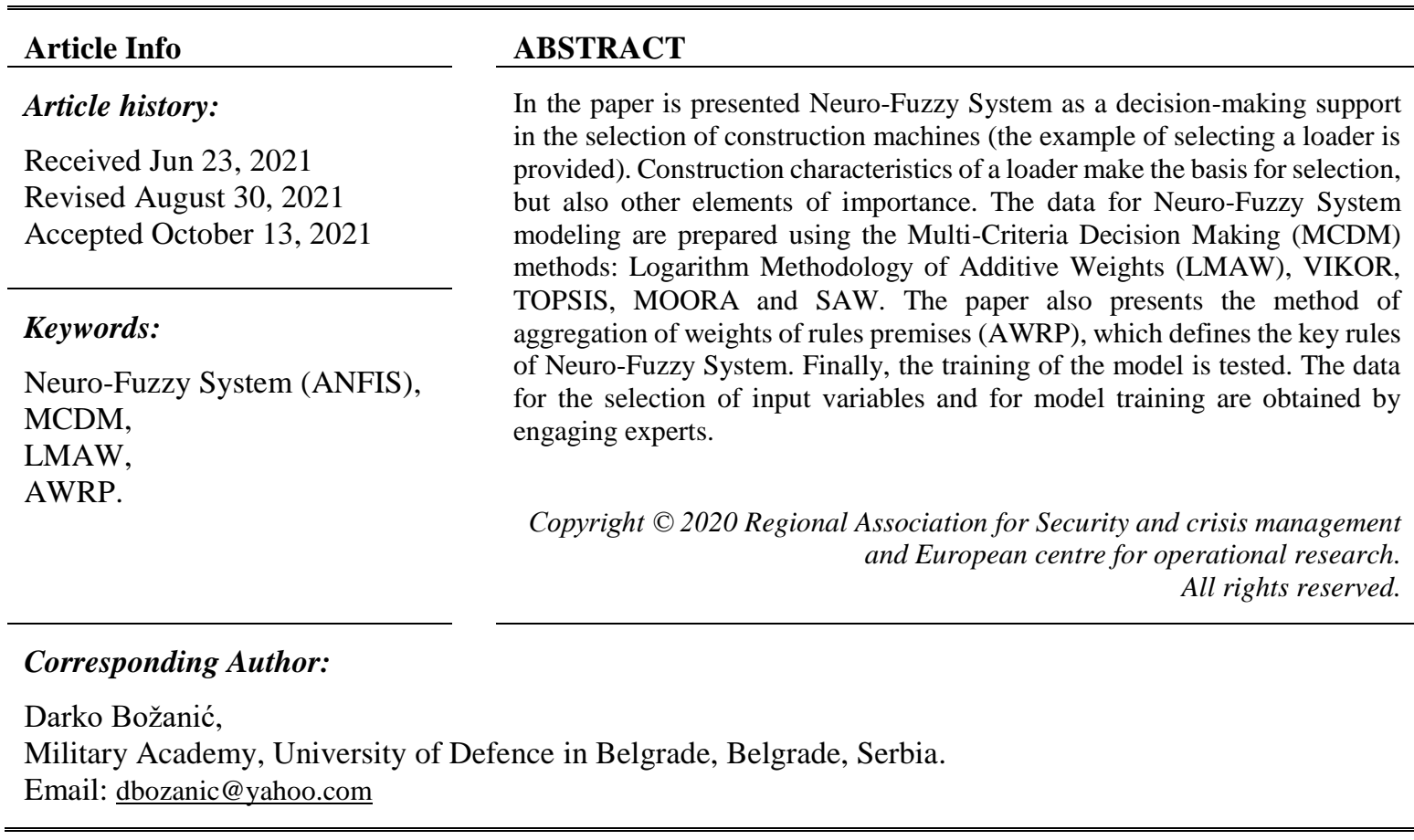

\section{INTRODUCTION}

Various machines are used for the performance of construction works, which replace manual work and increase efficiency and effectiveness. Construction machines are engaged in different jobs, earthworks, lifting loads, transport, concreting, etc. When it comes to earthworks, these are used for excavation, loading, transportation, opening, drilling, leveling, compaction of earth and other materials, and the basic representatives of this group of machines are: dozers, diggers, loaders, scrapers, graders, compaction machines (rollers, vibratory plates, etc.) and finishing machines. Loaders are construction machines for earthworks that are intended for excavation, transfer and loading of materials and earth. The working tool of a loader is a loading shovel/bucket, and a loader can move on wheels or caterpillar tracks.

In addition to the companies using construction machinery, the Serbian Army has engineering units in its composition, intended, among other things, to ensure the movement of other military units during operations, and use construction machinery for that purpose in additions to other means. Engineering units of the Serbian Army are equipped with construction machines for earthworks, intended primarily for the construction, repair and reconstruction of temporary military roads and the removal of obstacles, in order to ensure the mobility of other military units. (Božanić, et al, 2021).

Like any other army in the world, the Serbian Army strives to modernize its resources, by purchasing on the market, both domestic and international. This procedure is time consuming and extremely complex (Kuzmanović et al., 2017), and begins with the request of the engineering unit, including the necessary specific characteristics that the device should meet. Given that there is a large number of construction machines on the market with similar characteristics, different decision-making approaches can be used to help in making a procurement decision. 
Procurement of different types of means, both construction and transport, is a common topic in the decisionmaking literature. Radoičić (2009) uses the AHP method for the public purchase of vehicles. Kuzmanović et al. (2017) present the purchase of broadband radios using the AHP-TOPSIS hybrid model. Ibrahimović et al. (2019) present the FUCOM-MABAC model for the purchase of a transport vehicle, respectively, a tractor with a semi-trailer. Pamučar and Savin (2020) propose the BWM and the COPRAS models to select the optimal off-road vehicle for the needs of the Serbian Armed Forces. Ranking cars during the supply is presented in many papers using different methods: TOPSIS (Srikrishna et al., 2014), TOPSIS, VIKOR and SAW (Sathyapriya et al, 2018), AHP and TOPSIS (Ulkhaq et al., 2018), AHP (Byun, 2001), fuzzyANP (Yayla \& Yildiz, 2013). Cortes et al. (2012) use the AHP method for the procurement of trucks at the Colombian Shipyard. For the procurement of dozers for coal mining in the open pit, Jankovic et al. (2019) apply the AHP method. The selection of hydraulic loaders at the surface mines is presented by Đenadić et. al. (2019), who apply several methods of the MCDM: AHP, VIKOR, PROMETHEE, ELECTREE and TOPSIS. By applying the AHP-MOORA model it is solved the supply of a manual loader for pallets (Satoglu \& Türkekul, 2021). Rahimdel \& Bagherpour (2018) solve the supply of transport system for surface mines by DEMATEL-TOPSIS model.

Bearing in mind that there is a number of construction machines and that each of them has its own specifics, this paper presents the selection of a loader, which would best suit the existing needs of the engineering units of the Serbian Army. The problem of selecting a loader is presented in several papers. Kun et al. (2013) select a loader for marble extraction in Turkey by applying the AHP and TOPSIS method. The loader selection for Aegean Lignite Colliery by applying the AHP, Yager's method and fuzzy numbers is presented in the paper by Yavuz (2015). Waris et al. (2019) use the AHP method for the selection of a loader in Malaysian construction industry. Bazzazi et al. (2011) apply hybrid model based on the AHP method, entropy and VIKOR for the selection of a loader for surface mines, while Zhang et al. (2020) use a model based on the AHP, EDAS and entropy methods to purchase loaders.

Further is provided a description of the model applied. First, the applied methodology is explained, then a presentation of the model, respectively, the modeling of neuro-fuzzy system, is made and finally the obtained results are tested.

\section{DESCRIPTION OF THE APPLIED MEHTODOLOGY}

For the purpose of solving the presented problem, neuro-fuzzy system is modeled (such models can be found under another names in the papers: ANFIS - Adaptive Neuro Fuzzy Inference System; Adaptive Neural Network; Neuro-Fuzzy model). The algorithm for creating neuro-fuzzy system for selecting a loader is shown in the Figure 1.

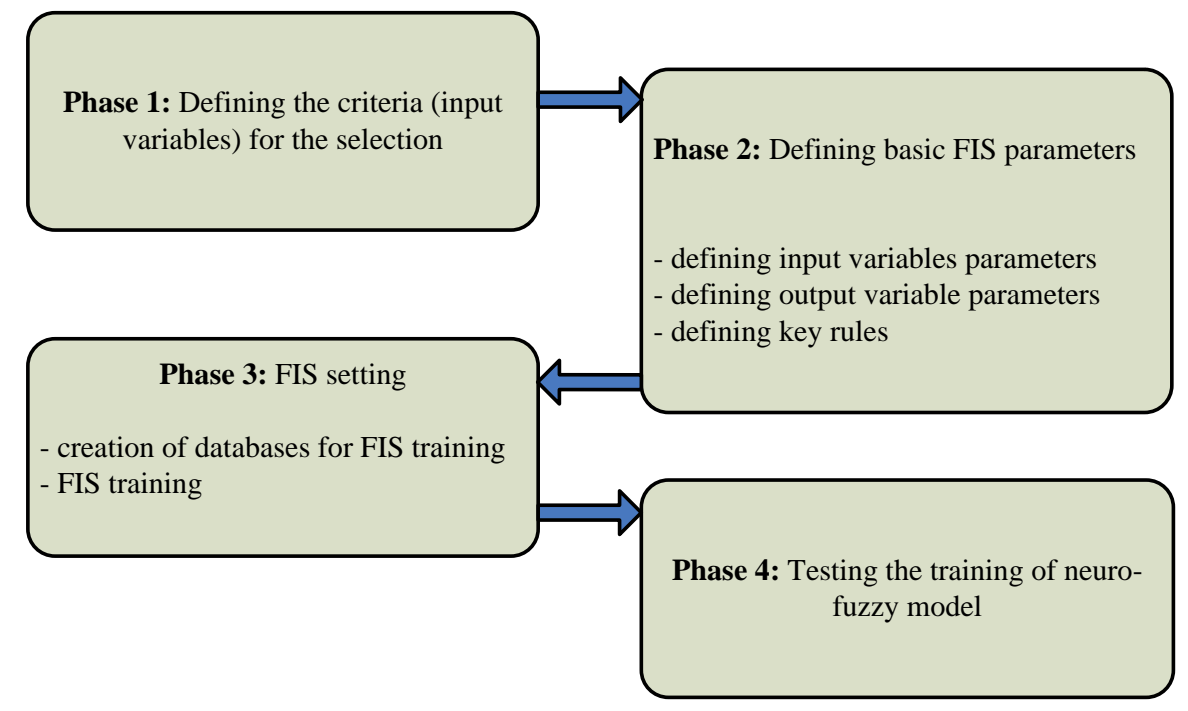

Figure 1. Overview of the processes for designing neuro-fuzzy system

As it is presented in the Figure 1, the modeling process consists of four phases. A more detailed elaboration of the applied methodology and modeling phase of neuro-fuzzy system for a loader selection is provided below. 


\subsection{Logarithm Methodology of Additive Weights (LMAW)}

The LMAW method was first published in the paper by Pamučar et al. (2021a). It consists of two parts, a part related to defining weight coefficients of criteria and a part related to the selection of the best alternative. So far, only the part related to defining weight coefficients of criteria has been applied in the papers, by applying various modifications. (Subotić et al., 2021; Pamučar et al., 2021b, Erdogan et al. 2021; Deveci et al., 2021).

Also in this paper, the method LMAW is used only for defining weight coefficients of criteria in group decision making by engaging experts $E=\left\{E_{1}, E_{2}, \ldots, E_{k}\right\}$. Steps of the method are further shown

Step 1. In the first step it is done the prioritization, by assigning higher value from the linguistic scale to the more significant criterion, and vice versa. That way it is obtained the priority vector $P^{e}=\left(\gamma_{C 1}^{e}, \gamma_{C 2}^{e}, \ldots, \gamma_{C n}^{e}\right)$, where $\gamma_{C n}^{e}$ presents the value from the linguistic scale assigned by the expert $e(1 \leq e \leq k)$ to the criterion $n$.

Step 2. In this step is defined the absolute anti-ideal point $\left(\gamma_{A I P}\right)$, in relation to the minimal values from the priority vector and this value should be lower than the lowest value of the priority vector.

Step 3: Defining the relation between the elements of the priority vector and the absolute anti-ideal point $\left(\gamma_{A I P}\right)$ is performed by applying the expression:

$$
\eta_{C n}^{e}=\frac{\gamma_{C n}^{e}}{\gamma_{A I P}}
$$

This way is obtained the expert relation vector $R^{e}=\left(\eta_{C 1}^{e}, \eta_{C 2}^{e}, . ., \eta_{C n}^{e}\right)$.

Step 4. In the fourth step is determined the vector of weight coefficients $w_{j}=\left(w_{1}, w_{2}, \ldots, w_{n}\right)^{T}$. The values of the weight coefficients of the criteria for the expert $e(1 \leq e \leq k)$ are obtained by applying the expression:

$$
\begin{aligned}
& w_{j}^{e}=\frac{\ln \left(\eta_{C n}^{e}\right)}{\ln \left(b^{e}\right)} \\
& b^{b}=\prod_{j=1}^{n} \eta_{C n}^{e}
\end{aligned}
$$

Step 5. Finally, by applying Bonferroni aggregator it is calculated the aggregated vector of the weight coefficients:

$w_{j}=\left(\frac{1}{k(k-1)} \sum_{\substack{i, j=1 \\ i \neq j}}^{k} w_{i}^{(e) p} w_{j}^{(e) q}\right)^{\frac{1}{p+q}}$

where $p, q \geq 0$ present stabilization parameters of the Bonferroni aggregator, $w_{j}^{e}$ presents weight coefficients obtained based on the assessment of the $e$-th expert.

\subsection{Neuro-fuzzy system}

Neuro-fuzzy systems present a unified concept of fuzzy logic and artificial neural networks. Neural networks and fuzzy logic present knowledge, reasoning and learning, however they use different approaches and have their own advantages and disadvantages. Fuzzy logic provides a reasoning mechanism with incomplete and insufficiently accurate information, and artificial neural networks provide some remarkable possibilities, such as the ability to learn, adapt, and generalize (Yuan \& Suarga, 1995). Neural networks can learn from the example, however, this type of knowledge is almost impossible to be described (Božanić et al., 2015). On the other hand, fuzzy logic provides approximate inference (Pamučar et al., 2016a), but it has no auto-adjustment feature. Neuro-fuzzy technique is based on the methods of fuzzy modeling and learning based on set database (Božanić et al, 2014). The calculation of the parameters of the membership functions takes place so that the corresponding Fuzzy Inference System (FIS) with the smallest error, corresponds to the given pairs of input-output data. This method of learning is similar to the method of learning of neural networks. 
Using a given input/output data set, a FIS is formed in which the parameters of the membership functions are set using certain algorithms. Such an approach allows the FIS to learn based on the data it models.

The development of neuro-fuzzy system consists of four phases.

Phase 1. Defining criteria (input variables). This step defines the criteria that influence the selection. Defining the criteria is done through a process of surveys and interviews with experts using the Delphi method.

Phase 2. Defining basic FIS parameters. In the process of defining basic parameters of a FIS, the most complicated part is defining the key rules. Different approaches are used to define the rules in a particular FIS as well as the key rules for neuro-fuzzy system. One of the most complicated is the survey of experts, most often using the Delphi method. This approach requires a large number of repetitions, due to the inconsistency of decision makers, which usually occurs due to a large number of rules. Also, the COMET method can be used (Salabun, 2015;Kizielewicz et al., 2020; Salabun et al., 2020). For determining key rules in this paper is used the method of aggregation of weights of rules premises (AWRP) (Božanić \& Pamučar, 2014; Pamučar \& Božanić, 2014), which is presented further.

The FIS basis consists of input-output variables which can be presented as ordered pairs:

$$
\left(x_{1}^{(1)}, \ldots, x_{n}^{(1)} ; y^{(1)}\right),\left(x_{1}^{(1)}, \ldots, x_{n}^{(2)} ; y^{(2)}\right), \ldots,\left(x_{1}^{(p)}, \ldots, x_{n}^{(q)} ; y^{(d)}\right)
$$

where $x_{1}^{(p)}, \ldots, x_{n}^{(q)}$ present the membership functions of the input variables $\mathrm{X}_{1}, \ldots, \mathrm{X}_{\mathrm{n}}$, and $y^{(1)}, \ldots, y^{(d)}$ present the membership functions of the output variables Y. A FIS can have more output variables. The procedure of the application of the AWRP method is identical, no matter the number of output variables. General overview of a FIS is provided in the Figure 2.

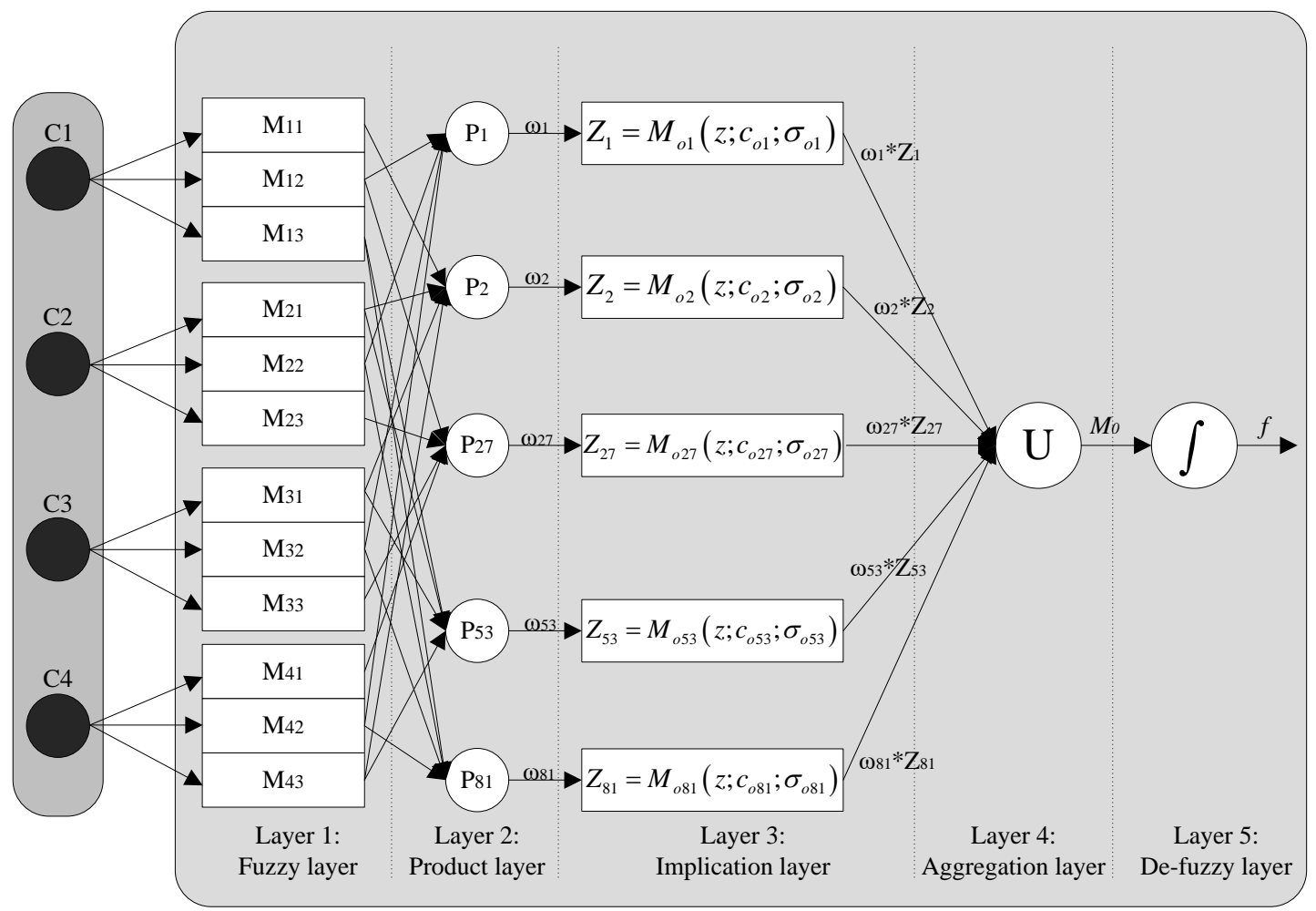

Figure 2. General overview of a FIS (Pamučar et al. 2016b)

The AWRP methods allows generating the base of fuzzy rules based on the input-output pairs (expression 5). A base of rules presents the link between the input ( $X_{i}$ ) and the output ( $Y$ ) variables of a FIS, where a FIS uses the base of rules (if-then) for obtaining output values

$f:\left(X_{1}, X_{2}, \ldots, X_{n}\right) \rightarrow Y$

Steps of the AWRP method are provided further (Božanić \& Pamučar, 2014; Pamučar \& Božanić, 2014). 
Step 2.1: Determining weight coefficients of input variables. Before the process of defining weight coefficients of input variables are defined basic terms: set of input variables $X_{i}(i=1,2, \ldots, n)$ - where $n$ presents the number of input variables; membership functions of input variables $x_{i}^{(i)}(i=1, \ldots, m)$ - where $m$ presents the number of membership functions which describe the input variable; output variable $Y$; membership functions of the output variable $y^{(i)}(i=1, \ldots, d)$ - where $d$ presents total number of membership functions which describe the variable.

The weight coefficient $\left(w_{X_{i}}\right)$ of the input variable $X_{i}$ is obtained by applying the LMAW method which is described in the section 2.1. of this paper. Instead of the presented procedure within this step is possible to use another methods for determining weights of criteria, such as the methods shown in Milićević \& Župac (2012a, 2012b).

Step 2.2: Determining type and number of the membership functions of the input-output FIS variables. After obtaining the weight coefficients of the FIS input variables $\left(w_{X_{i}}\right)$, type and number of the membership functions of the input $\left(X_{i}\right)$ and output $(Y)$ variables are determined. Further, it is determined confidence interval of the membership functions:

$$
\begin{aligned}
& x_{1}^{(1)}, x_{1}^{(2)}, \ldots, x_{1}^{(i)} \in\left[x_{1}^{-}, x_{1}^{+}\right] ; x_{2}^{(1)}, x_{2}^{(2)}, \ldots, x_{2}^{(j)} \in \\
& {\left[x_{2}^{-}, x_{2}^{+}\right] ; \ldots, x_{m}^{(1)}, x_{m}^{(2)}, \ldots, x_{m}^{(k)} \in\left[x_{m}^{-}, x_{m}^{+}\right]} \\
& y^{(1)}, y^{(2)}, \ldots, y^{(i)} \in\left[y^{-}, y^{+}\right]
\end{aligned}
$$

Step 2.3. Determining weight coefficients of the membership functions of the input variables $w_{x_{i}}^{(i)}(i=1, \ldots, m)$. The weight coefficients of the membership functions of the input variables $w_{x_{i}}^{(i)}$ should meet the following condition:

$$
\sum_{j=1}^{m} w_{x_{i}}^{(i)}=w_{X_{i}}
$$

The distribution of the weight coefficients of the membership functions should be realistic as much as possible. It can be even and uneven.

Step 2.4. Generating initial ("non complete") base of rules with the maximal number of combinations of the input-output pairs. The maximum number of rules depend on the number of the membership functions and it is determined by applying the expression:

$$
B_{p}=\prod_{i=1}^{n} k_{x_{i}}
$$

where $B_{p}$ presents the number of rules, and $k_{X_{i}}$ presents the number of the membership functions for each input variable.

Initial basis of rules consists only of the premise ("if" part of the rule), respectively, the combination of all the membership functions of the FIS input variables $\left(x_{i}^{(i)}\right)$. Initial ("non-complete") basis of rules $R$ is presented in matrix form:

$$
\begin{aligned}
& \begin{array}{llll}
X_{1} & X_{2} & \ldots & X_{n}
\end{array} \\
& R=\stackrel{R_{2}}{R_{1}}\left(\begin{array}{ccccc}
x_{1}^{(1)} & x_{2}^{(1)} & \ldots & x_{n}^{(1)} \\
\vdots & x_{1}^{(2)} & x_{2}^{(1)} & \ldots & x_{n}^{(2)} \\
\vdots & \vdots & \ldots & \vdots \\
R_{c} & x_{1}^{(m)} & x_{2}^{(m)} & \ldots & x_{n}^{(m)}
\end{array}\right)
\end{aligned}
$$

Step 2.5. Generating "complete" base of rules - Assigning adequate conclusions $\left(y^{(i)}\right)$ to the premises $x_{i}^{(i)}$ . Generating "complete" base of rules starts with creating the matrix $R^{\prime}$ in which the combinations of the input pairs are changed with the weight coefficients $\left(w_{x_{i}}^{(i)}\right)$ : 


$$
R^{\prime}=\left(\begin{array}{ccccc}
w_{x_{1}}^{(1)} & w_{x_{2}}^{(1)} & w_{x_{3}}^{(1)} & \ldots & w_{x_{1}}^{(1)} \\
w_{x_{1}}^{(2)} & w_{x_{1}}^{(2)} & w_{x_{3}}^{(2)} & \ldots & w_{x_{1}}^{(2)} \\
w_{x_{1}}^{(3)} & w_{x_{2}}^{(3)} & w_{x_{3}}^{(3)} & \ldots & w_{x_{n}}^{(3)} \\
\ldots & \ldots & \ldots & \ldots & \ldots \\
w_{x_{1}}^{(m)} & w_{x_{2}}^{(m)} & w_{x_{3}}^{(m)} & \ldots & w_{x_{n}}^{(m)}
\end{array}\right)
$$

After the creation of the matrix $R^{\prime}$ are summed the elements of the matrix by rows by applying the expression:

$$
w_{y}=\sum_{i=1}^{n} w_{x_{i}}^{(i)} \cdot y^{+}, y^{+} \in\left[y^{-}, y^{+}\right]
$$

where $y^{+}$presents top border of the confidence interval $\left[y^{-}, y^{+}\right]$of the output variable $Y$, and vice versa.

Further it is necessary to determine the degree of membership of the real number (crisp value) $w_{y}$ to the membership function $\left(y^{(i)}\right)$ of the output variable $Y$ :

$$
y^{(i)}=\max \left(w_{y} \cap \mu_{y^{(i)}}\right)
$$

Step 2.6. Optimization of the number of rules (elimination of extra rules). During the generation of the basis of rules to each pair of the membership functions of the input variables is assigned adequate membership function of the output variable. Elimination of extra rules is performed in the cases when there are two or more rules with similar or the same combinations of the membership functions of the input/output variables. In such cases, it is kept the rule whose sum of weight coefficients of the membership functions (included in the rule) is the highest:

$$
R=\max \left(\sum w_{x_{R}}^{(i)}\right), \mathrm{i}=1,2, \ldots n
$$

where $w_{x_{R}}^{(i)}$ presents the weight coefficient of the membership functions included in the rule $R$.

In the cases when neuro-fuzzy models are created, only key rules are singled out from the created rule base which best reflect the relations of input and output variables.

Phase 3. FIS setup. After defining the initial FIS, the development of neuro-fuzzy system is started, respectively, the training of the initial FIS. FIS is transferred into a five-layer neuro-fuzzy network. The data obtained by selected MCDM methods for ranking alternatives are used for FIS training. The selection of the methods is made through four steps described below (Božanić, 2017).

Step 3.1. Defining alternatives and MCDM methods. For the purpose of obtaining training data, a set of alternatives that best reflect already defined key rules is defined, as well as an arbitrary set of MCDM methods.

Step 3.2. Ranking of defined alternatives. In the second step, the criteria functions of the alternatives are calculated using the MCDM methods defined in the previous step. The weight coefficients of the criteria are calculated by the LMAW method, described in the previous section.

Step 3.3. Spearman's rank correlation coefficient. Applying the Spearman's coefficient, the correlation of ranks obtained with the MCDM methods and the rank derived on the basis of key rules is calculated, according to the expression:

$$
S=1-\frac{6 \sum_{i=1}^{n} D_{i}^{2}}{n\left(n^{2}-1\right)}
$$

where $D_{i}$ presents the difference in ranks, and $n$ - the number of ranked elements.

Step. 3.4 Selection of methods. Based on Spearman's coefficient, the MCDM methods are selected for creating a database for training neuro-fuzzy systems. From the selected set of methods, those methods are selected where the Spearman's coefficient is equal to one, the others are discarded.

After selecting the method, a set of arbitrary values of input variables is generated. The set should cover the whole spectrum of values, from the lowest to the highest, in order for the results to be as realistic as possible. The selected MCDM methods are then applied, and finally the results of the methods are aggregated using Bonferroni aggregators, as in the expression (4) (or some others such as: Hara et al. (1998), Dombi (1982), 
Pamučar (2020), Riaz et al. (2021), Ali et al (2021), Zulqarnain et al. (2021), etc). With the obtained results, the training of the initial FIS is performed, respectively, its adjustment.

Phase 4. Testing the training of neuro-fuzzy models. Through this phase, the quality of the decisions that the modeled system gives at the output is checked. In cases where the output is not satisfactory, all or part of the initial FIS parameters are redefined, and the whole training process is repeated.

\section{MODELING OF NEURO-FUZZY SYSTEM FOR RANKING LOADERS}

Further is presented neuro-fuzzy model for a loader selection. How to reach the final model is shown below.

\subsection{Description of criteria - input variables and calculation of the weight coefficients of criteria}

As a part of the research, the selection of the criteria or input variables was first defined. The selection was made through three rounds of repetition with eight experts, using surveys and interviews. For the purposes of solving this problem, five criteria were defined:

- Criteria 1 (C1): Price of construction machinery - presents the monetary value of goods on the market $(€)$.

- Criteria 2 (C2): Maintenance costs - Determining costs within the life cycle of a technical system or a product (Life Cycle Costing - LCC) is a process of economic analysis to assess the total cost of supply (acquisition), ownership during operation in regular and possibly revitalized service life, as well as product recall costs (Papić \& Milovanović, 2007). Alternatives by the criterion are assessed in $€$.

- Criteria 3 (C3): Theoretical work performance - is defined as production in a unit of time, expressed by volume, weight or piece, depending on the nature of production. The calculation of the theoretical work performance of the loader is done by applying the expression (Hristov, 1978):

$U_{p}=\frac{60 * q}{t_{c}}\left[m^{3} / h\right]$

where $q$ presents the volume of the loading bucket, and $t_{c}$ the time of the cycle expressed in minutes.

- Criteria 4 (C4): Structural properties of the machine - This criterion presents the parameters of the structure, namely: engine power, speed, volume of the working tool, unloading height, degree of complexity of kinematic schemes, etc. (Božanić, et al., 2021).

- Criteria 5 (C5): Reliability - The reliability of construction machinery is usually defined as the probability of performing a particular function, without error, under given conditions, over a period of time.

The criteria $\mathrm{C} 1, \mathrm{C} 2$ and $\mathrm{C} 3$ belong to the group of numerical, while the criteria $\mathrm{C} 4$ and $\mathrm{C} 5$ belong to the group of linguistic criteria and are defined by five linguistic descriptors: very low (VL) - 1, low (L) - 2, medium (M) - 3, high $(\mathrm{H})-4$, and very high $(\mathrm{VH})-5$. The criteria $\mathrm{C} 1$ and $\mathrm{C} 2$ are cost-type, while other criteria are of benefit type.

In the next step of data preparation for neuro-fuzzy model, the calculation of the weight coefficients of criteria is performed using the LMAW method. After prioritization of the criteria, the mathematical apparatus of the LMAW method, presented in the previous section, is applied. The obtained values of weight coefficients are provided in the Table 1.

Table 1. Weight coefficients of the criteria

\begin{tabular}{ccc}
\hline Criteria & $w$ & Rank \\
\hline C1 2 & 0.192 & 3 \\
C2 3 & 0.103 & 5 \\
C4 & 0.301 & 1 \\
C5 & 0.225 & 2 \\
\hline
\end{tabular}

\subsection{Design of neuro-fuzzy system}

The neuro-fuzzy model was created in the MATLAB software package. First, the appearance and number of membership functions were defined for each input-output variable. The input variables are described by a 
Gaussian curve the: input variable $\mathrm{C} 2$ with three membership functions, the input variables $\mathrm{C} 1$ and $\mathrm{C} 5$ with four, while other input variables are defined with five membership functions each. Takagi-Sugeno FIS is commonly used in neuro-fuzzy models. In the specific case, 9 constants are defined for the output variable (decision preference). At this initial stage of model development, membership functions are not specifically adjusted. In the Figure 3 is shown the appearance of the model.

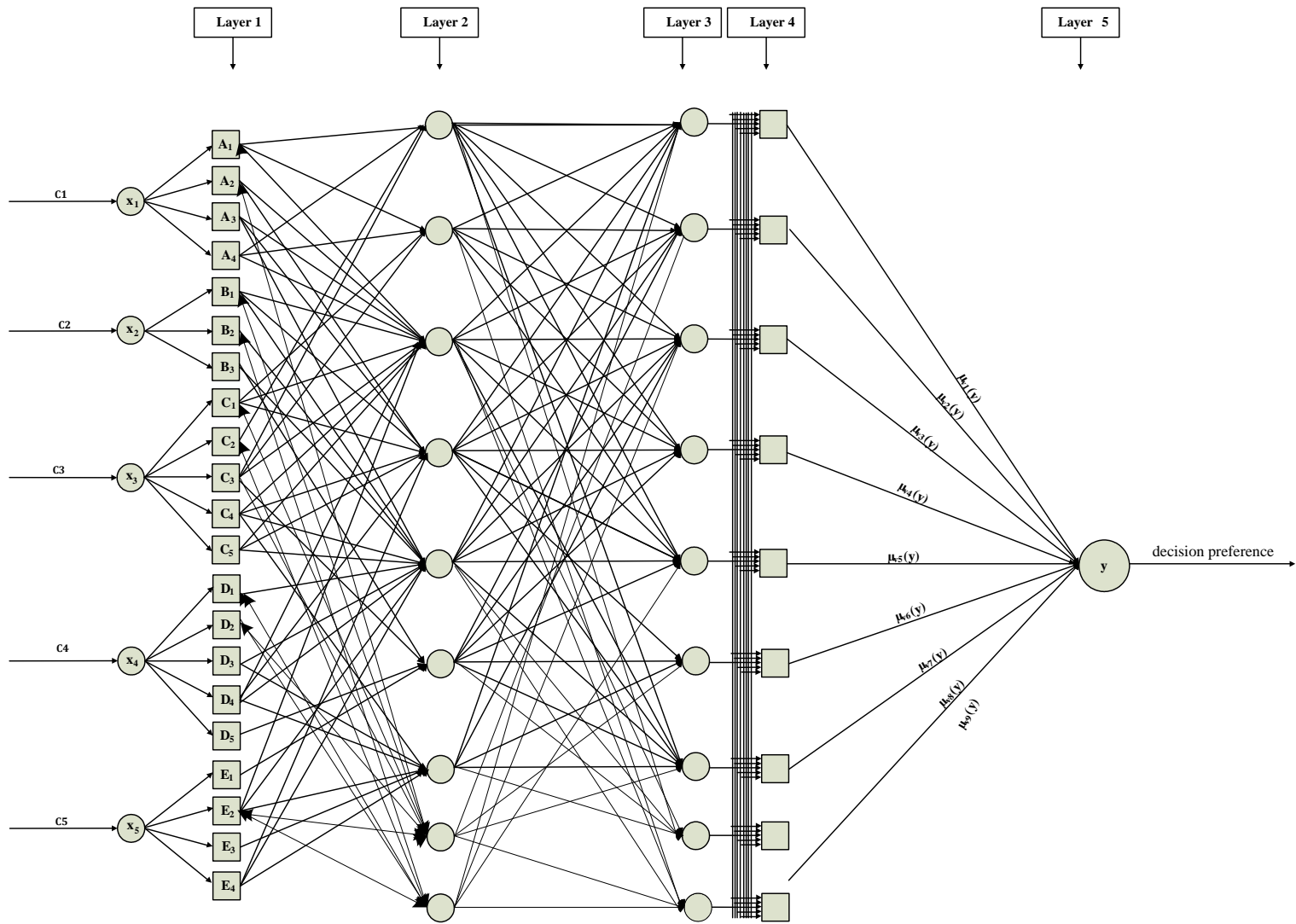

Figure 3. Structure of neuro-fuzzy model

In the next step, the key rules are defined. This process is performed using the AWRP method. Through the interviewing of experts, the weight coefficients of each membership function of the input variable are obtained, as in the Table 2.

Table 2. Weight coefficients of the membership function criteria

\begin{tabular}{ccccccc}
\hline Criteria & $w$ & $w_{1}^{(i)}$ & $w_{2}^{(i)}$ & $w_{3}^{(i)}$ & $w_{4}^{(i)}$ & $w_{5}^{(i)}$ \\
\hline C1 & 0.192 & 0.067 & 0.057 & 0.045 & 0.023 & - \\
C2 & 0.103 & 0.04 & 0.033 & 0.03 & - & - \\
C3 & 0.301 & 0.071 & 0.070 & 0.069 & 0.049 & 0.042 \\
C4 & 0.225 & 0.047 & 0.041 & 0.049 & 0.043 & 0.045 \\
C5 & 0.179 & 0.045 & 0.042 & 0.044 & 0.048 & - \\
\hline
\end{tabular}

Further, the base of all rules is defined, from which nine key rules are selected. In this way, the initial FIS is defined, which is ready for training. In order to obtain training data, the MCDM methods are first selected. The initial set consists of the following methods: VIKOR (Opricović \& Gwo-Hshiung, 2004), TOPSIS (Hwang \& Yoon, 1981), MOORA (Brauers \& Zavadskas, 2006), SAW (Zionts \& Wallenius, 1983) and COPRAS (Zavadskas \& Kaklauskas, 1996). Ranking the alternatives that best reflect the key rules, is done by applying the previously mentioned methods. The only minor deviation in the range of alternatives is observed with the COPRAS method, so in this case it is rejected, respectively, the training data are obtained by applying the remaining mentioned methods (VIKOR, TOPSIS, MOORA, SAW). In order for the neuro-fuzzy model to be better trained, a set of 2000 training data is defined. The training is performed using a back-propagation 
algorithm in 4000 epochs. The average error at the end of the training is 0.0198 , which is acceptable in decision support systems.

\section{TESTING TRAINING OF NEURO-FUZZY MODEL}

Having done the training of neuro-fuzzy model, it should be done the testing (Pokorni, 2021). The verification is performed through three steps, which are described below.

Step. 1: In the first step, the analysis of the influence of input variables on the output is performed, respectively, the verification of whether the values of input parameters give illogical decision preferences. The analysis confirmed that there were no sudden or unexpected deviations, that is, a decrease in the output variable when there are minor changes in the input parameters. A graphical example of the dependence of the output variable in relation to the criteria $\mathrm{C} 3$ is given in the Figure 4.

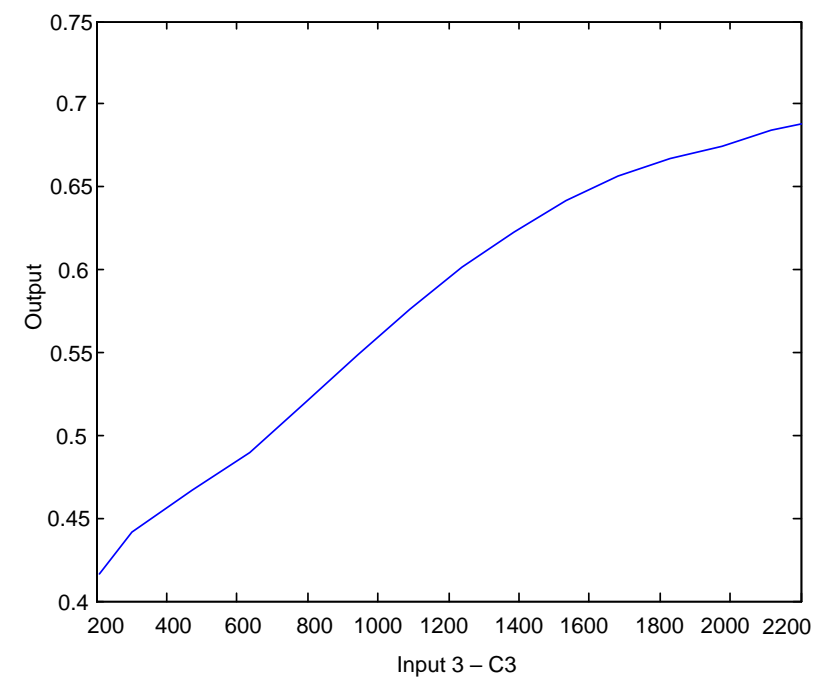

Figure 4. Graphical overview of the dependence of the decision preference on the criterion C3

Step 2: In this step, a comparison is made of the output results with which the network was trained and the output results obtained by applying neuro-fuzzy model, when the input data with which the model was trained are entered in the model. With this procedure, only minor deviations are observed, which are part of the average error at the end of the training.

Step 3: In the last step, six alternatives are selected, which are evaluated according to each defined criterion. The mentioned set of alternatives is evaluated by applying the developed model by experts, and the obtained results are compared. In the Table 3 are provided the evaluations of the proposed alternatives by criteria..

Table 3. Characteristics of alternatives for testing the training of neuro-fuzzy model

\begin{tabular}{cccccc}
\hline Criteria & C1 & C2 & C3 & C4 & C5 \\
\hline A1 & 63,940 & $2,557.60$ & 1028.57 & $\mathrm{H}$ & $\mathrm{M}$ \\
A2 & 69,850 & $2,794.00$ & 1080.00 & $\mathrm{M}$ & $\mathrm{H}$ \\
A3 & 47,090 & $1,883.60$ & 1038.46 & $\mathrm{~L}$ & $\mathrm{~L}$ \\
A4 & 71,520 & $2,860.80$ & 955.75 & $\mathrm{M}$ & $\mathrm{M}$ \\
A5 & 67,000 & $2,680.00$ & 1047.27 & $\mathrm{~L}$ & $\mathrm{H}$ \\
A6 & 70,850 & $2,834.00$ & 1372.88 & $\mathrm{H}$ & $\mathrm{M}$ \\
\hline
\end{tabular}

In the Figure 5 is presented the rank of alternatives according to the data from the Table 3. 


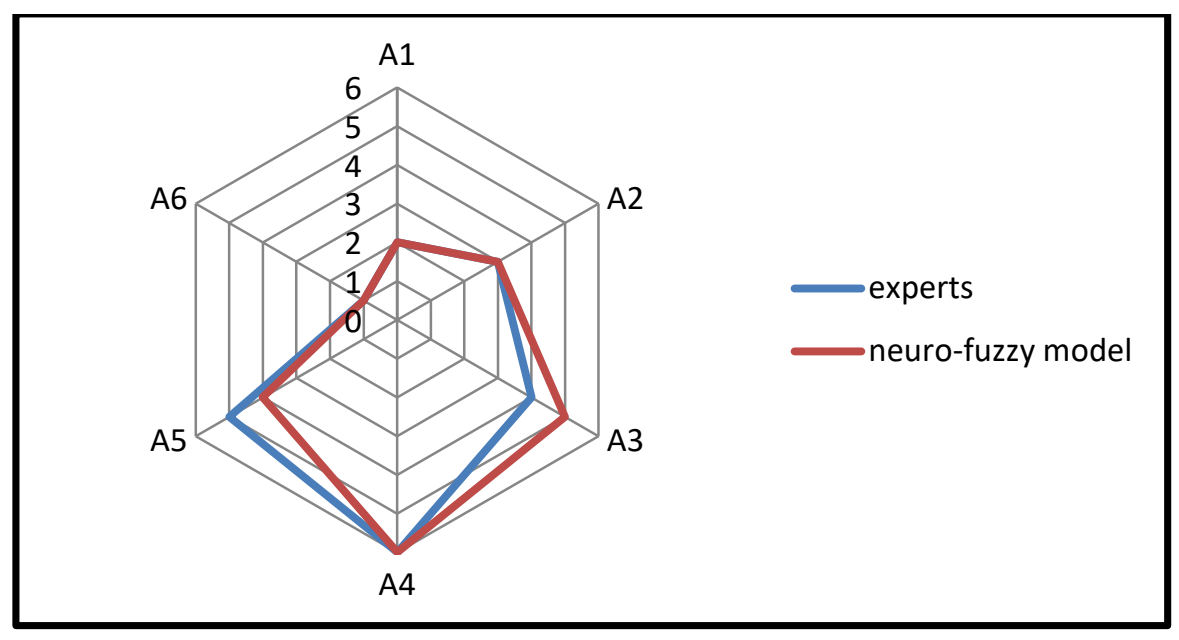

Figure 5. Rank of alternatives for testing neuro-fuzzy model

As can be seen from the Figure 5, only the alternatives A3 and A5 replaced their positions. Considering that these are the fourth and fifth-ranked alternative, it does not have a significant impact on the final decision. Spearman's rank correlation coefficient is 0.94 , which is a very high correlation rank. Accordingly, the neurofuzzy model can be considered trained.

\section{CONCLUSION}

The Serbian Army dedicates significant attention to the selection of the machines in use, and a loader is one of these machines. The rapid development of construction machinery in the world, often brings into dilemma decision makers which machine to choose. In this context, it is developed the presented Neuro-Fuzzy system.

The presented model provides one approach in the selection of a loader, which is based on gathering expert knowledge. In addition to defining the criteria for the selection of a loader, the paper also presents a specific methodology for the development of Neuro-Fuzzy system. The key rules necessary for model training are defined using the AWRP method, while the training data are creates by using the MCDM methods: LMAW, VIKOR, TOPSIS, MOORA and SAW. The use of Bonferroni aggregators in aggregating expert opinions also gives specific weight to the paper.

The developed model provides significant support to decision makers for several reasons. The problem of selection is considered entirely with the persons who have significant experience in this field - experts, which in later decision-making gives the opportunity to the persons with less experience to make an adequate decision. The model has the possibility of further learning - adjustment, respectively, adaptation. By training with new data, the accuracy of the model can be increased.

In future research, based on the presented methodology, models for the selection of other construction machines, such as dozers, diggers, graders, rollers, etc, can be defined.

\section{References}

Ali, Z., Mahmood, T., Ullah, K., \& Khan, Q. (2021). Einstein Geometric Aggregation Operators using a Novel Complex Interval-valued Pythagorean Fuzzy Setting with Application in Green Supplier Chain Management. Reports in Mechanical Engineering, 2(1), 105-134.

Bazzazi, A.A., Osanloo, M. \& Karimi, B. (2011). Deriving preference order of open pit mines equipment through MADM methods: Application of modified VIKOR method. Expert Systems with Applications, 38(3), 2550-2556.

Božanić, D. (2017). Model of decision support in overcoming water obstacles in Army combat operations, (Only in Serbian: Model podrške odlučivanju pri savlađivanju vodenih prepreka u napadnoj operaciji Kopnene vojske). Doctoral dissertation, Belgrade: University of Defence in Belgrade, Military Academy. 
Božanić, D., \& Pamučar D. (2014). Making of Fuzzy Logic System rules base for decision making support by Aggregation of Weights of Rules Premises, Tehnika, 69 (1), 129-138.

Božanić, D., Karović, S., \& Pamučar, D. (2014). Adaptive neural network for the selection of course of action as a prerequisite of the cost price estimate of an offensive army operation. Vojno delo, 66(4), 148-162.

Božanić, D., Milić, A., Tešić, D., Sałabun, W., \& Pamučar, D. (2021). D numbers - FUCOM - fuzzy RAFSI model for selecting the Group of construction machines for enabling mobility. Facta Universitatis, Series: Mechanical Engineering, 19(3), 447-471

Božanić, D., Slavković, R., \& Karović, S. (2015). Model of fuzzy logic application to the assessment of risk in overcoming the water obstacles during an army defensive operation. Vojno delo, 67(4), 240-260.

Brauers, W. K. M., \& Zavadskas, E. K. (2006). The MOORA method and its application to privatization in a transition economy. Control and Cybernetics, 35(2), 443-468.

Byun, D.-H. (2001). The AHP approach for selecting an automobile purchase model. Information \& Management. 38, 289-297.

Đenadić, S. P., Jovančić, P. D., Ignjatović, D. M., Miletić, F. M., \& Janković, I. V. (2019). Analysis of the application of multi-criteria methods in optimizing the selection of hydraulic excavators on open-cast coal mining. Tehnika, 74(3), 369-377.

Deveci, M., Pamučar, D., Gokasar, I. (2021). Fuzzy Power Heronian function based CoCoSo method for the advantage prioritization of autonomous vehicles in real-time traffic management, Sustainable Cities and Society, 69, 102846.

Dombi, J.A. (1982). General class of fuzzy operators, the demorgan class of fuzzy operators and fuzziness measures induced by fuzzy operators. Fuzzy Sets and Systems, 8, 149-163.

Erdogan, N., Pamučar, D., Kucuksari, S., Deveci, M. (2021). An integrated multi-objective optimization and multi-criteria decision-making model for optimal planning of workplace charging stations, Applied Energy, 304, 117866

Hara, T., Uchiyama, M., \& Takahasi, S.E. (1998). A refinement of various mean inequalities. Journal of Inequalities and Applications, 2(4), 387-395.

Hristov, S. (1978). Organization of engineering works (Only in Serbian: Organizacija inžinjerijskih radova). Belgrade: VIZ.

Hwang, C. L., \& Yoon, K. (1981). Multiple attribute decision making: a state of the art survey: Lecture Notes in Economics and Mathematical Systems, vol. 186. Berlin: Springer-Verlag.

Ibrahimović, F. I., Kojić, S. L., Stević, Ž. R., \& Erceg, Ž. J. (2019). Making an investment decision in a transportation company using an integrated FUCOM-MABAC model. Tehnika, 74(4), 577-584.

Jankovic, I., Djenadic, S., Ignjatovic, D., Jovancic, P., Subaranovic, T., \& Ristovic, I. (2019). Multi-Criteria Approach for Selecting Optimal Dozer Type in Open-Cast Coal Mining. Energies, 12(12), 2245-2260.

Kizielewicz, B, Wątróbski, J, \& Sałabun, W. (2020). Identification of Relevant Criteria Set in the MCDA Process-Wind Farm Location Case Study. Energies, 13(24), 6548.

Kun, M., Topaloglu, S., \& Malli, T. (2013). Evaluation of Wheel Loaders in Open Pit Marble Quarrying by Using the AHP and Topsis Approaches. Archives of Mining Sciences, 58, 255-267.

Kuzmanović, B., Kovačević, M., \& Terzić, M. (2017). Application of multi-criteria analysis methods (AHP and TOPSIS) in the procurement of the wideband radio receivers. Proceedings of the XLIV Symposium on Operational Research (SYM-OP-IS), Zlatibor, Serbia, 646-651.

Milićević, R. M., \& Župac Ž. G. (2012a). An objective approach to determining criteria weights. Vojnotehnički glasnik/Military Technical Courier, 60(1), 39-56.

Milićević, R. M., \& Župac Ž. G. (2012b). Subjective approach to the determination of criteria weights. Vojnotehnički glasnik/Military Technical Courier, 60(2), 48-70. 
Opricović, S., \& Gwo-Hshiung T. (2004). The Compromise solution by MCDM methods: A comparative analysis of VIKOR and TOPSIS. European Journal of Operational Research, 156(2), 445-455.

Pamučar, D. \& Božanić, D. (2014). Overview of the new method for development of the base of the Fuzzy Logic Systems for decision making support rules - Premisa Rules Weight Aggregation method. Proceedings of the XLI Symposium on Operational Research (SYM-OP-IS), Divčibare, Serbia, 368-373.

Pamučar, D. (2020). Normalized weighted geometric Dombi Bonferroni mean operator with interval grey numbers: Application in multicriteria decision making. Reports in Mechanical Engineering, 1(1), 44-52.

Pamučar, D., \& Savin, S. (2020). Multiple-criteria model for optimal off-road vehicle selection for passenger transportation: BWM-COPRAS model. Vojnotehnički glasnik/Military Technical Courier, 68(1), 28-64.

Pamučar, D., Božanić, D., \& Komazec, N. (2016a). Risk Assessment of Natural Disasterts using Fuzzy Logic System Type-2. Management- Journal for Theory and Practice Management, 21(80), 23-32.

Pamučar, D., Božanić, D., \& Milić, A. (2016b). Selection of a course of action by Obstacle Employment Group based on a fuzzy logic system. Yugoslav Journal of Operations Research, 26(1), 75-90.

Pamučar, D., Žižović, M., Biswas, S., \& Božanić, D. (2021a). A new Logarithm Methodology of Additive Weights (LMAW) for multi-criteria decision-making: Application in logistics. Facta Universitatis, Series: Mechanical Engineering, 19(3), 361-380.

Pamučar, D., Deveci, M., Gokasar, I., Popović, M. (2021b). Fuzzy Hamacher WASPAS Decision-Making Model for Advantage Prioritization of Sustainable Supply Chain of Electric Ferry Implementation in Public Transportation. Environment, Development and Sustainability, 13, 1397.

Papić, Lj., \& Milovanović, Z. (2007). System Maintainability and ReliabilityEdition. Prijevor: The research Center of Dependability and Quality Managament.

Pokorni, S. (2021). Current state of the application of artificial intelligence in reliability and maintenance. Vojnotehnički glasnik/Military Technical Courier, 69(3), 578-593.

Radoičić, G. (2009). Implementation of methods for multicriteria decision in the sample of public purchase from practice. Journal of Applied Engineering Science, 7(23-24), 15-26.

Rahimdel, M.J., \& Bagherpour, R. (2018). Haulage system selection for open pit mines using fuzzy MCDM and the view on energy saving. Neural Computing and Applications, 29, 187-199.

Riaz, M., Farid, H.M.A., Aslam, M., Pamučar, D., \& Božanić, D. (2021). Novel Approach for Third-Party Reverse Logistic Provider Selection Process under Linear Diophantine Fuzzy Prioritized Aggregation Operators. Symmetry, 13(7), 1152.

Sałabun, W. (2015). The Characteristic Objects Method: A New Distance-based Approach to Multicriteria Decision-making Problems. Journal of Multi-Criteria Decision Analysis, 22, 37-50.

Sałabun, W., Shekhovtsov, A., Pamučar, D., Wątróbski, J., Kizielewicz, B., Więckowski, J., Bozanić, D., Urbaniak, K., \& Nyczaj, B. (2020). A Fuzzy Inference System for Players Evaluation in Multi-Player Sports: The Football Study Case. Symmetry, 12(12), 2029, 1-49.

Sathyapriya, S., Bavya Seeli, P., \& Swathi, R. (2018). Selection of cars using combined multi criteria decision making techniques. International Journal of Creative Research Thoughts (IJCRT), 6(1), 82-841.

Satoglu, S.I., \& Türkekul, İ. (2021). Selection of Material Handling Equipment using the AHP and MOORA. Jurnal Teknik Industri, 22(1), 113-124.

Srikrishna, S., Reddy, S., \& Vani, S.G. (2014). A New Car Selection in the Market using TOPSIS Technique. International Journal of Engineering Research and General Science, 2(4), 177-181.

Subotić, M., Radičević, V., Pavlović, Z., \& Ćirović, G. (2021). Development of a New Risk Assessment Methodology for Light Goods Vehicles on Two-Lane Road Sections. Symmetry, 13(7), 1271.

Ulkhaq, M.M., Wismar, R., Wijayanti, M., Zain, S., Baskara, E., \& Leonita, W. (2018). Combining the AHP and TOPSIS to evaluate car selection. Proceedings of the 2nd International Conference on High Performance Compilation, Computing and Communications (HP3C). Association for Computing Machinery, New York, NY, USA, 112-117. 
Waris, M., Panigrahi, S., Mengal, A., Soomro, M., Mirjat, N., Ullah, M., Azlan, Z., \& Khan, A. (2019). An Application of Analytic Hierarchy Process (AHP) for Sustainable Procurement of Construction Equipment: Multicriteria-Based Decision Framework for Malaysia. Mathematical Problems in Engineering, 2019, 1-20.

Yavuz, M. (2015). Equipment selection based on the AHP and Yager's method. Journal of the Southern African Institute of Mining and Metallurgy, 115(5), 425-433.

Yayla, A.Y, \& Yildiz, A. (2013). Fuzzy Analitic Network Process based Multi Criteria Decision Making methodology for a family automobile purchasing decision. South African Journal of Industrial Engineering, 24, 167-180.

Yuan, Y., \& Suarga, S. (1995). On the Integration of Neural Networks and Fuzzy Logic Systems, International Conference on Systems, Man and Cybernetics, Vancouver, Canada, 452-456.

Zapata C.J.A., Arango, S.M.D., \& Moreno, M.S.P. (2012). ExpertchoiceC decision support system implementation for vehicle selection in a colombian shipyard. Dyna, 79(173), 53-60.

Zavadskas, E. K., \& Kaklauskas, A. (1996). Determination of an efficient contractor by using the new method of multicriteria assessment. International Symposium for "The Organisation and Management of Construction". Shaping Theory and Practice Vol. 2 (pp. 94-104). Bury St. Edmunds, Su olk: St. Edmudsbury Press.

Zhang, F., Ju, Y., Santibanez-Gonzalez, E.D., \& Wang, A. (2020). SNA-based multi-criteria evaluation of multiple construction equipment: A case study of loaders selection. Advanced Engineering Informatics, 44, 101056.

Zionts, S., \& Wallenius, J. (1983). An interactive multiple objective linear programing method fora a class of underlying nonlinear utility fuctions. Management Science, 29(5), 519-529.

Zulqarnain, R. M., Siddique, I., Ali, R., Pamučar, D., Marinković, D., \& Božanić, D. (2021). Robust Aggregation Operators for Intuitionistic Fuzzy Hypersoft Set With Their Application to Solve MCDM Problem. Entropy, 23(6), 688. 